\title{
Patient preferences for types of community-based cardiac rehabilitation programme
}

\author{
Shermain Chia, ${ }^{1}$ Xin Yi Wong, ${ }^{2}$ Min Li Toon, ${ }^{3}$ Yi Seah, ${ }^{4}$ Angela Frances Yap, ${ }^{1}$ \\ Cindy Lim, ${ }^{5}$ Hung Yong Tay, ${ }^{5}$ Warren Fong, ${ }^{6}$ Lian Leng Low, ${ }^{7}$ Yu Heng Kwan ${ }^{5,8}$
}

- Additional material is published online only. To view please visit the journal online (http://dx.doi.org/10.1136/ heartasia-2017-010976).

${ }^{1}$ Duke-NUS Medical School, Singapore

2Department of Pharmacy, National University of Singapore, Singapore

${ }^{3}$ Yong Loo Lin School of Medicine, National University of Singapore, Singapore ${ }^{4}$ Faculty of Dentistry, National University of Singapore, Singapore

${ }^{5}$ Heart Wellness Centre, Singapore Heart Foundation, Singapore

${ }^{6}$ Department of Rheumatology and Immunology, Singapore General Hospital, Singapore Department of Family Medicine and Continuing Care, Singapore General Hospital, Singapore

${ }^{8}$ Program in Health Services and Systems Research, Duke-NUS

Medical School, Singapore

\section{Correspondence to} Yu Heng Kwan, Program in Health Services and Systems Research, Duke-NUS Medica School, Singapore 169857; yuheng@u.duke.nus.edu

Received 1 November 2017 Revised 5 January 2018 Accepted 9 January 2018

\section{ABSTRACT \\ Introduction Cardiac rehabilitation (CR) improves mortality, morbidity and quality of life of cardiovascular patients. However, its uptake is poor especially in the hospitals due to long travel distances and office hours constraints. Community-based CR is a possible solution. Objectives To understand the type of community- based CR preferred and identify patient characteristics associated with certain programme combinations. Methods A cross-sectional survey was administered to a randomised list of patients at risk for or with cardiovascular diseases at two community-based CR centres. Participants were presented with nine hypothetical choice sets and asked to choose only one of the two alternative programme combinations in each choice set. Attributes include support group presence, cash incentives, upfront deposit and out- of-pocket cost. The counts for each combination were tallied and corrected for repeats. Chi-square test and logistic regression were performed to understand the characteristics associated with the preferred CR combination.}

Results After correcting for repeats, patients most (85.2\%) prefer CR programmes with new group activities, support group, cash rewards, deposit and out-of-pocket cost, and few exercise equipment with physiotherapist presence without the need for monitoring equipment. Patients with more than three bedrooms in their house are less likely (OR 0.367; $\mathrm{Cl} 0.17$ to 0.80; $\mathrm{P}=0.011$ ) to choose the choice with no physiotherapist and few equipment available.

Conclusion This is the first study to explore patients' preferences for different types of community CR. Higher income patients prefer physiotherapist presence and are willing to settle for less equipment. Our study serves as a guide for designing future community-based CR programmes.

\section{INTRODUCTION}

Cardiovascular disease such as ischaemic heart disease (IHD) is one of the leading causes of mortality and disability globally, ${ }^{1}$ and its disease burden is increasing with an ageing population. ${ }^{2}$ In 2010 , there were 62.5 million new cases of cardiovascular disease, of which 24.2 million were from IHD. ${ }^{3}$ This number is predicted to rise to 84 million new cardiovascular disease cases in $2030 .^{3}$

Cardiac rehabilitation (CR) is one intervention aimed at controlling the burden of IHD. It features components of behavioural counselling and an exercise programme, designed to maximise physical, psychological and social functioning. Evidence show that CR improves mortality, morbidity and quality of life for patients with IHD. ${ }^{4}$ However, its uptake throughout the world is poor. ${ }^{5}$ This is even more apparent in the hospital setting where patients have to travel long distances and hospital programmes are only available during office hours. ${ }^{6}$

A potential way to circumvent this issue is to offer community-based CR. ${ }^{78}$ However, the uptake rate remains unclear. There is also limited evidence of what constitutes the factors that affect the uptake of such programme. ${ }^{9}$

Hence, the aim of this study is to understand the types of community-based CR programme preferred by patients undergoing CR and to identify patient characteristics that are associated with certain combinations of programme. This would be valuable for future modifications to maximise programme uptake and improve long-term patient outcomes.

\section{METHODS}

\section{Participants and setting}

An institutional review board-approved survey was administered to patients suffering from or at risk for cardiovascular diseases at two community-based CR centres. Participants were at Phase 3 and Phase 4 of their CR. ${ }^{10}$ Trained interviewers took written consent and administered the paperand-pencil surveys. Interviews were conducted in either English or Mandarin.

\section{Randomisation of sample}

A list of active CR participants at two community-based CR centres was collated and assigned a random number from 0 to 1 using Microsoft Excel. After sorting the random assigned numbers in ascending order together with the corresponding names, the first 291 on the list are chosen to be approached by interviewers before or after their next CR sessions. This is to minimise bias during sampling.

\section{Survey structure}

The survey first gathers data on sociodemographic characteristics of the participants. Number of bedrooms correlates well with income level ${ }^{11}$ and are often used as proxies of income in government policies and research studies. ${ }^{12}$

Each participant was then presented with nine hypothetical choice sets (generated using Sawtooth V.9.3.1 software), each consisting of two combinations of programme attributes, and asked to choose the combination they preferred. Participants are given a brief explanation of the various programme features. They will be required to choose only one 
of the two alternative programme combinations for each choice set. This method of surveying is suggested in order to reduce the cognitive burden on participants, as compared with choosing from all the combinations at one go. ${ }^{13}$

The study explored eight attributes (online supplementary figure 1). All attributes and their levels were finalised after a comprehensive systematic review, in-depth interview with patients and the final set of attributes were agreed on with clinicians and physiotherapists. ${ }^{9}$ The attributes were namely new group activities, presence of a support group, availability of exercise equipment, presence of physiotherapist, types of incentives/rewards (cash, sporting equipment or healthy food), presence of monitoring equipment that measure participant vital signs, amount of refundable deposit for a total of 10 sessions and out-of-pocket cost per exercise session.

\section{Quality control of survey}

Cognitive interviews were conducted before the start of the surveys. This allowed the survey to be understandable by laypeople and the meaning of the questions understood in a similar way across all interviewees. Participants were presented with seven choice sets in the survey (an example of which is given in online supplementary figure 2), with two additional choice sets for quality control. One of the additional choice sets was for dominance testing (choice set with one combination clearly dominating the other to ensure that participants carefully reviewed the choice sets). The remaining additional choice set was for retesting (repetition of a choice set to assess test-retest reliability).

\section{Statistical analysis}

Descriptive statistics were presented in mean (SD) or number (\%). To quantify the most popular choice combination, counts were analysed by summating each choice combination by the participants. Repeated combinations were adjusted for by dividing the total counts by the number of times they were repeated in the survey.

Chi-square test was conducted to assess which of the two combinations was preferred within each choice set with the corresponding $\mathrm{P}$ value noted. Following which, logistic regression was performed for the choice combination against the various participant characteristics/demographics in order to understand which characteristic/demographic is associated with the preferred combination. The corresponding OR, 95\% CI and $P$ value were presented. $P$ values less than 0.05 were considered statistically significant. All analyses were conducted using STATA SE14.0 for Windows.

\section{RESULTS}

\section{Participants}

A total of 265 participants out of the 291 approached were recruited and all completed the study (table 1 ). The mean age was 65.7 (8.8) years, with $161(60.8 \%)$ men. Most participants were married $(84.5 \%)$ and half (49.9\%) received at least secondary school education.

\section{Participants' preference for the various combinations}

The number of participants who preferred each particular combination are listed in table 2 . From simple counting, the top three combinations were combinations 8 (198 participants, 98.4\%), 5 (192 participants, 90.6\%) and 12 (179 participants, 85.2\%) before correction, and combinations 12 (179 participants,

\begin{tabular}{|c|c|}
\hline Participant characteristics & $\begin{array}{l}\mathrm{N}=265 \\
\text { No }(\%)\end{array}$ \\
\hline Age (years) $\pm S D$ & $65.7 \pm 8.8$ \\
\hline \multicolumn{2}{|l|}{ Gender } \\
\hline Male & $161(60.8)$ \\
\hline Female & $104(39.2)$ \\
\hline \multicolumn{2}{|l|}{ Race } \\
\hline Chinese & $242(91.3)$ \\
\hline Non-Chinese & $23(8.7)$ \\
\hline \multicolumn{2}{|l|}{ Highest education level } \\
\hline Secondary and below & $134(50.6)$ \\
\hline Above secondary education & $131(49.4)$ \\
\hline \multicolumn{2}{|l|}{ Marital status } \\
\hline Married & $223(84.5)$ \\
\hline Not married & $41(15.5)$ \\
\hline \multicolumn{2}{|l|}{ No of bedrooms* } \\
\hline Three rooms and below & $96(36.4)$ \\
\hline More than three rooms & $168(63.6)$ \\
\hline \multicolumn{2}{|l|}{ Employment status* } \\
\hline Employed & $82(31.1)$ \\
\hline Not employed & $182(68.9)$ \\
\hline Hypertension & $150(56.6)$ \\
\hline Diabetes & $62(23.4)$ \\
\hline Hyperlipidaemia & $192(72.5)$ \\
\hline Overweight & $70(26.4)$ \\
\hline Valvulopathy & $23(8.7)$ \\
\hline Ischaemic heart disease (IHD) & $158(59.6)$ \\
\hline \multicolumn{2}{|l|}{ Past intervention done } \\
\hline $\mathrm{PCl}$ & $73(27.5)$ \\
\hline CABG & $51(19.2)$ \\
\hline \multicolumn{2}{|l|}{ Type of prevention for IHD } \\
\hline Primary & $107(40.4)$ \\
\hline Secondary & $158(59.6)$ \\
\hline
\end{tabular}

85.2\%), 1 (174 participants, 82.1\%) and 8 (153.5 participants, 72.4\%) after correcting for repeats.

Patients showed a statistically significant preference in all choice sets except for choice sets $3(\mathrm{P}=1)$ and $5(\mathrm{P}=0.68)$. The findings are reported in table 2. Participants prefer combination $1(82.1 \%)$ over $2,3(73.5 \%)$ over $4,5(90.6 \%)$ over $7,8(93.4 \%)$ over 10 and $12(85.2 \%)$ over 11 , with $\mathrm{P}<0.001$ for each pair of combination.

\section{Participants' prioritisation of cardiac rehabilitation attributes by participant characteristics}

Choice 7A includes new group activities, support group, cash rewards, many exercise equipment, deposit and out-of-pocket cost, but no physiotherapist presence or monitoring equipment. Comparatively, choice 7B has physiotherapist presence but less exercise equipment. Patients whose houses have more than three bedrooms are less likely to choose choice 7A (OR 0.37 ; CI 0.17 to $0.80 ; \mathrm{P}=0.011$ ) over choice $7 \mathrm{~B}$.

\section{DISCUSSION}

This is the first study to explore patients' preference for different types/combinations of community CR programme. We used a novel method using count analysis of multiple paired choices to 


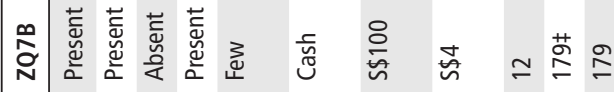

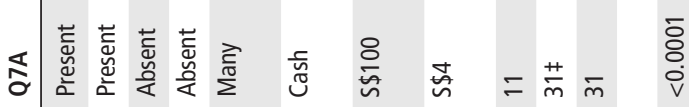

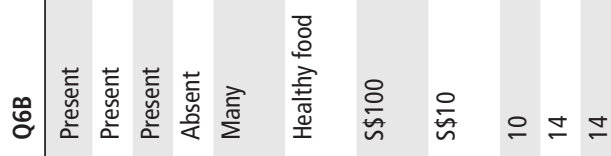

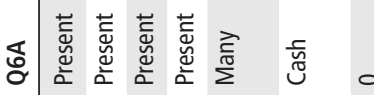

๓

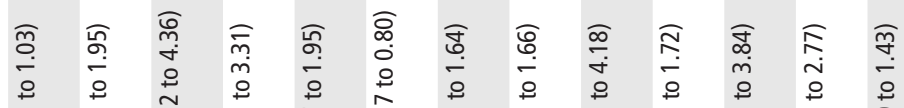

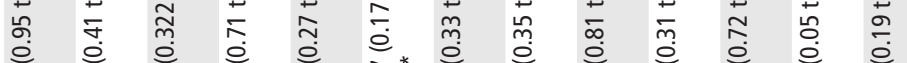
б

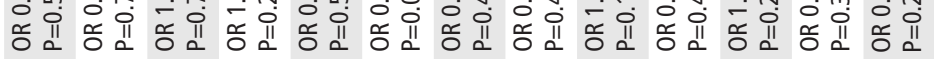

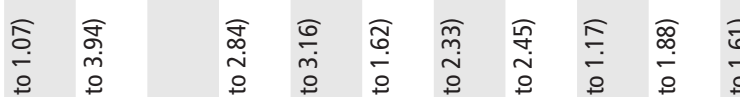
กิ

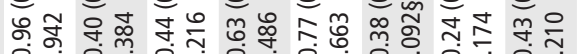

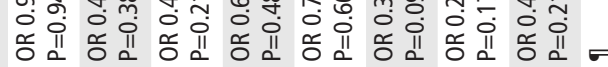

药

용 ֻे ำ ิำ क्ष III

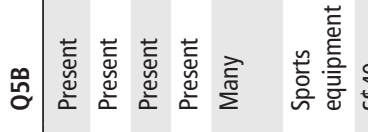

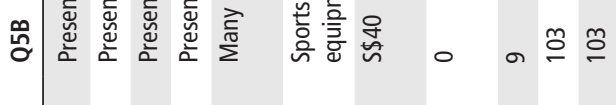

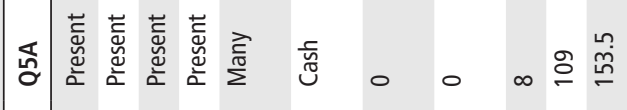
용

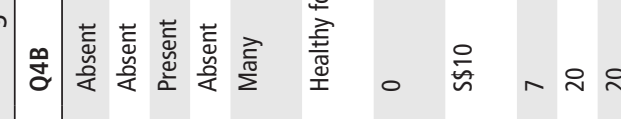

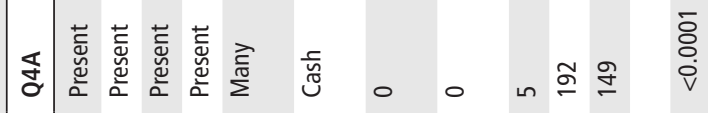

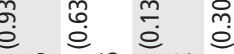

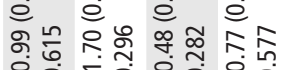

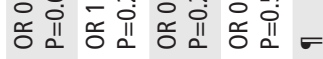

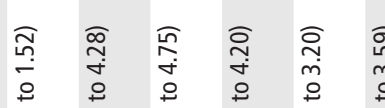

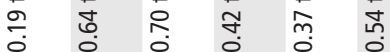

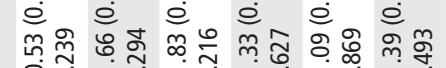

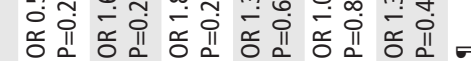

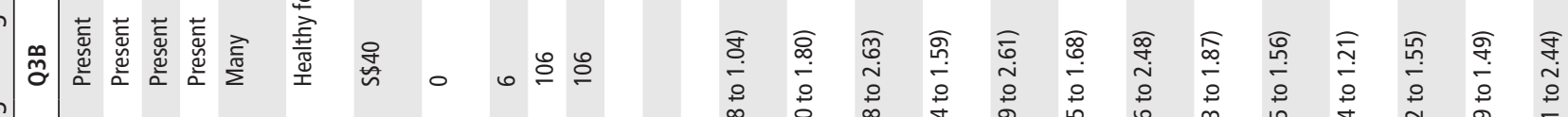
品

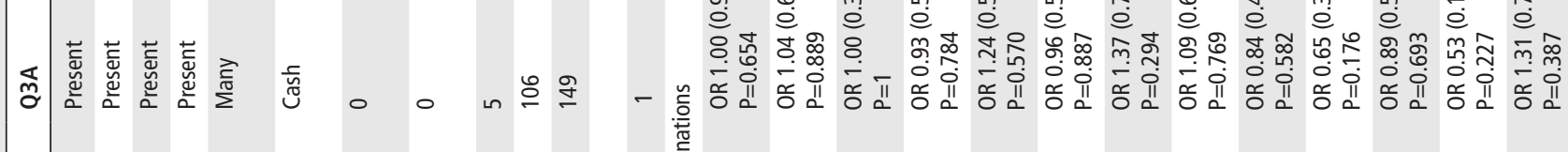

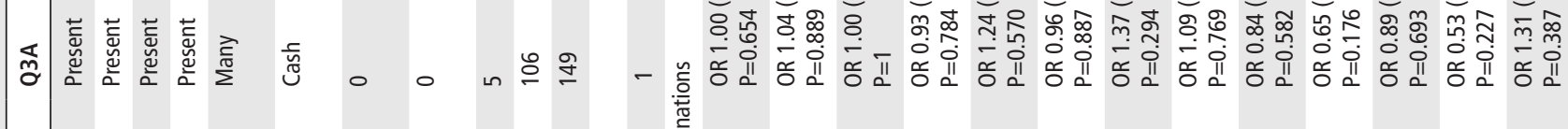

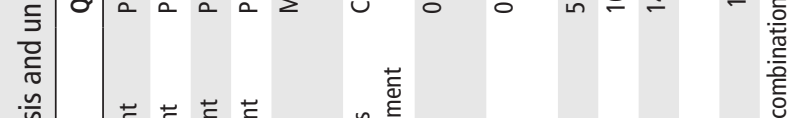

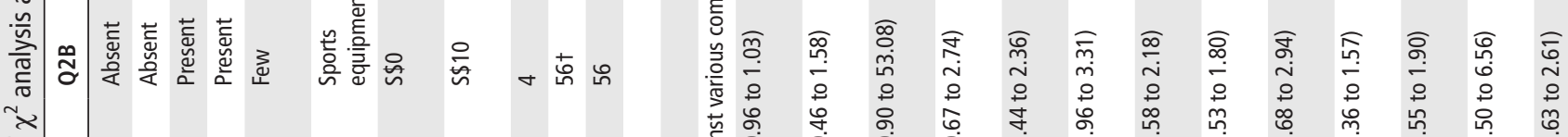




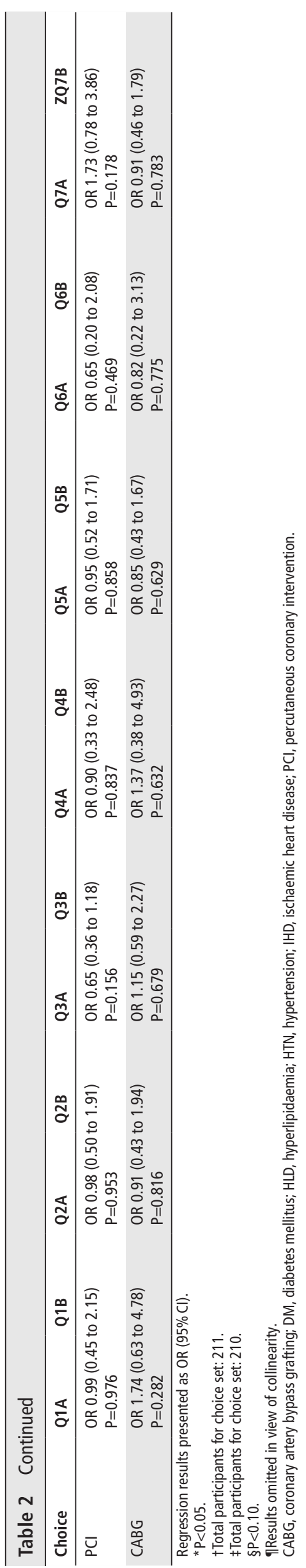

establish a preferred programme and the factors associated with it while reducing cognitive burden to CR patients. ${ }^{13}$

The participants sampled were mostly elderly (81.8\%) (defined here above the age of 60 years), who were at higher risk of cardiovascular diseases. ${ }^{14}$ Hence, a CR programme would be beneficial for the primary and secondary prevention of cardiovascular diseases. The sociodemographics of our sampled population is also similar to that of Singapore's general population in terms of gender ratio, education level and type of housing, ${ }^{15}$ but with a greater proportion of Chinese.

Our study indicates that patients with more than three bedrooms in their house (as a proxy for higher income levels) prefer the presence of a physiotherapist during their sessions and are willing to settle for less equipment in exchange. This finding could serve as a guide during the planning of future CR programme involving higher income participants and thereby improve their long-term adherence to community-based CR.

As CR programme in Singapore is not covered by insurance but paid for by the participants themselves, the cost of the programme may become an important influencing factor and causes respondents to choose the combination that is free. However, as shown in our results in table 2, the most popular combination chosen has a cost involved. Hence, the overall package of attributes still matters.

There are some limitations in our study. First, the relative importance participants gave to each attribute (eg, support group presence) could not be fully understood. This could be further explored in future studies that take the form of discrete conjoint experiments (DCEs) ${ }^{16}$ which we are planning for the next phase of our study. Next, the study provided only insight into a limited number of stated attributes whose levels were narrowed in clear definition. This could be corrected by increasing the number of attributes explored in the study, but might come at the cost of increased cognitive burden to survey participants. ${ }^{13}$ Finally, our sample size may be limited and may restrict the generalisability of the results to other patients. However, we are the first study to explore patient preferences for different combinations of CR programme using this unique method and serve as a foundation for future DCE studies.

Despite its limitations, this study provides insight into stated preferences on the type of community-based CR programme and lays the foundation to plan a DCE by understanding our patients better. We acknowledged that it may be more suitable to decrease the number of choice sets but offer more alternative programme combinations in each choice set, and understanding their preferences, but this method had been found to introduce significant cognitive burden and reduce participation rate.

In addition, even though patient preference is important, this must be taken into consideration as a whole with perspective of clinical safety and effectiveness of exercise prescription that is modified as and when required by a qualified cardiopulmonary physiotherapist. These factors may then help to improve adherence and uptake of CR programme. ${ }^{17}$

\section{CONCLUSION}

The study explores preferences of patients undergoing community-based CR. Higher income patients prefer the presence of a physiotherapist and are willing to settle for less equipment in exchange. This could serve as a guide for designing future community-based CR programmes and advise on the design of future DCE studies. 


\section{Key messages}

What is already known about this subject? Cardiac rehabilitation (CR) improves mortality, morbidity and quality of life of cardiovascular patients. However, its uptake is poor especially in the hospitals due to long travel distances and office hours constraints. Community-based CR is a possible solution to this.

\section{What does this study add?}

This is the first study to explore patients' preferences for different types of community CR. It aims to understand the type of community-based CR preferred and identify patient characteristics associated with certain programme combinations.

\section{How might this impact on clinical practice?}

Our study serves as a guide for designing future communitybased CR programmes.

Contributors YHK is the principal investigator of the study while XYW, AFY, HYT and $\mathrm{CL}$ are co-investigators. WF and LLL reviewed the articles included for the study. $\mathrm{SC}$ is the MD candidate conducting this study. She is responsible for study design, reviewing of articles and presentation of data. The first draft of the manuscript was prepared by SC.

Funding This research received no specific grant from any funding agency in the public, commercial or not-for-profit sectors.

Competing interests None declared.

Patient consent Detail has been removed from this case description/these case descriptions to ensure anonymity. The editors and reviewers have seen the detailed information available and are satisfied that the information backs up the case the authors are making.

Ethics approval This study has been approved by the National University of Singapore Institutional Review Board (NUS-IRB) guidelines.

Provenance and peer review Not commissioned; externally peer reviewed.

(c) Article author(s) (or their employer(s) unless otherwise stated in the text of the article) 2018. All rights reserved. No commercial use is permitted unless otherwise expressly granted.

\section{REFERENCES}

1 Lozano R, Naghavi M, Foreman K, et al. Global and regional mortality from 235 causes of death for 20 age groups in 1990 and 2010: a systematic analysis for the Global Burden of Disease Study 2010. Lancet 2012;380:2095-128.

2 Barquera S, Pedroza-Tobías A, Medina C, et al. Global overview of the epidemiology of atherosclerotic cardiovascular disease. Arch Med Res 2015;46:328-38.

3 Bloom DE, Cafiero ET, Jané-Llopis $\mathrm{E}$, et al. The global economic burden of noncommunicable diseases: World Econ Forum, 2011.

4 Br Assoc Cardiovasc Prev Rehabil. BACPR standards and core components for cardiovascular disease prevention and rehabilitation 2012. 2nd edn: Br Assoc Cardiovasc Prev Rehabil.

5 Krittanawong C, Tweet MS, Hayes SE, et al. Usefulness of cardiac rehabilitation after spontaneous coronary artery dissection. Am J Cardiol 2016;117:1604-9.

6 Horwood H, Williams MJ, Mandic S. Examining motivations and barriers for attending maintenance community-based cardiac rehabilitation using the health-belief model. Heart Lung Circ 2015;24:980-7.

7 Ong KY, Yap E, May Fen Chia Y, et al. Impact of community-based cardiac rehabilitation on clinical parameters of patients with cardiovascular diseases. ASEAN Heart J 2016;24.

8 Kwan YH, Ong KY, Tay HY, et al. Heart wellness programme: a pilot communitybased cardiac rehabilitation programme in a multiethnic society. Singapore Med $J$ 2016;57:188-90.

9 Kwan YH, Yap AF, Tay HY, et al. Exploring product-specific attributes of a community cardiac rehabilitation program in an Asian urban city. Value Health Reg Issues 2017;12:50-6.

10 Poh R, Ng HN, Loo G, et al. Cardiac rehabilitation after percutaneous coronary intervention in a multiethnic Asian country: enrollment and barriers. Arch Phys Med Rehabil 2015;96:1733-8.

11 Low LL, Wah W, Ng MJ, et al. Housing as a social determinant of health in Singapore and its association with readmission risk and increased utilization of hospital services. Front Public Health 2016;4:109.

12 Statistics SDo. Key household income trends: Singapore Department of Statistics, 2016.

13 Reed Johnson F, Lancsar E, Marshall D, et al. Constructing experimental designs for discrete-choice experiments: report of the ISPOR Conjoint Analysis Experimental Design Good Research Practices Task Force. Value Health 2013;16:3-13.

14 Savji N, Rockman CB, Skolnick AH, et al. Association between advanced age and vascular disease in different arterial territories: a population database of over 3.6 million subjects. J Am Coll Cardiol 2013;61:1736.

15 Singapore DoS. Singapore in figures 2017, 2017.

16 Lancsar E, Louviere J. Conducting discrete choice experiments to inform healthcare decision making: a user's guide. Pharmacoeconomics 2008;26:661-77.

17 Achttien RJ, Vromen T, Staal JB, et al. Development of evidence-based clinical algorithms for prescription of exercise-based cardiac rehabilitation. Neth Heart J 2015;23:563-75 